\title{
Roma Community in the Hotel and Gastronomic Services in the Czech Republic
}

\author{
Marek Merhaut \\ Institute of Hospitality Management in Prague, Czech Republic
}

Copyright $(2017$ by authors, all rights reserved. Authors agree that this article remains permanently open access under the terms of the Creative Commons Attribution License 4.0 International License

\begin{abstract}
Romani culture does not differ from the culture of gadjo. It has its purpose, namely the maintenance of the community and family at its very core. At the same time we have to always bear in mind that Romani culture, as other cultures, is not static but dynamic, and is influenced by a number of variations and changes. Inevitably, social changes lead to cultural changes. The reality of Romani culture is a complicated and multi-layered problem that has to be solved in the future. The matter of employment of Romani people in hospitality and gastronomy has its origin in their education. Romani children are not very much interested in jobs of cooks or waiters, and they do not apply for studies at secondary schools providing gastronomy and hospitality education. A Romani student is considered rather an exception.
\end{abstract}

Keywords Romani Culture, Employment, Hospitality and Gastronomy, School, Discrimination

\section{Introduction}

At the present time there live about 200,000 to 300,000 Roma in our country. And in the process of our country's heading towards Europe, the issue of racism and intolerance is increasing. It is also one of the most serious problems of suspending both Czech and foreign politicians and the press. Where does this racism come from? The answer is not simple, because the emergence of racism has different causes. How are we now solving the Roma issue? It has become a nightmare for the members of the Parliament and ministers as there is no political either social concept for solutions. Liberal confidence in the fact that the Roma ethnic group after the fall of the communist regime uses (represented by its elite) restored democracy in order to promote their long-term interests, has proved to be an illusion. There is a hope that the Roma ethnic group "exfoliate" layer of those who wish to experience social advancement and as for the rest, the government intends to "moderate their marasmus".
In the name of the rights of the Roma people they, in their own lifestyle, forget company's obligations to ensure the right of Roma children of school education, adequate health care, often they make their day of care for eating, since family products are often used differently.

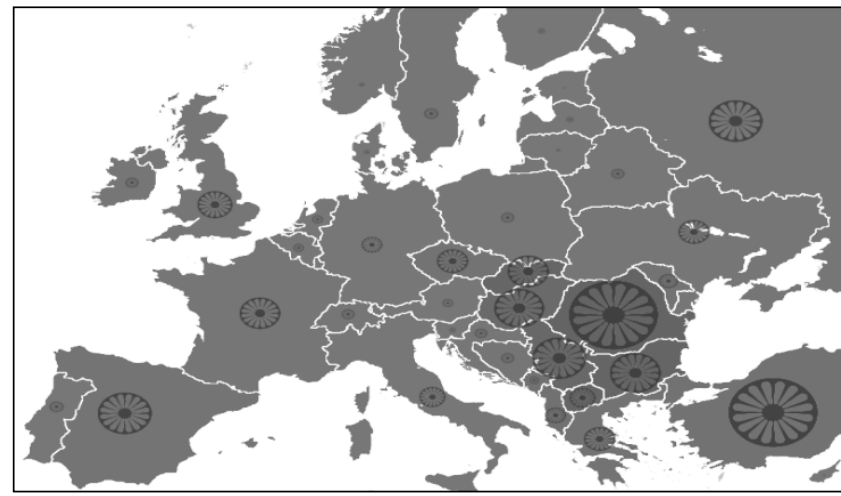

Source: http://cs.wikipedia.org/wiki/Romov

Chart 1. The Roma population - the average occupancy distribution

Since the middle Ages when Romani people first appeared in Europe it has been a great challenge for historians to search for their original homeland. The date of their arrival in Europe cannot be accurately determined because different groups of Romani have spread in Europe independently, each in their own way. One can only rely on existing records in town archives. The data in the archives appear there only in connection with some events indicating what can be called an official advent of Roma people but not their exact arrival. In contemporary chronicles there are many wandering magicians entertaining feudal lords, dancers dressed scantily but in bright colors popular at men's courts and hated by pious and respectable citizens. Thus, Romani people could be confused with wandering bands of artists. Then in about 14th century a human community which differed from other residents in darker skin, clothes, distinctive way of life, completely incomprehensible language, temper, and unwillingness to subordinate to pressure of the majority population began to wander and move from place to place [1]. 
Medieval scholars asked questions such as who the Romani people in Europe were, where they came from, and what their original homeland was. For centuries Europe failed to answer these questions. The mysterious origin of Romani was also connected with a distance between them and the rest of the population, which has remained in existence up to now [6]. Nowadays the Indian origin of Romani people is proven indisputably. Mainly it was thanks to the comparison of the Romani language with Indian dialects, which contributed to confirmation of this hypothesis. Due to the lack of historical sources the exact date of the Romani exodus from India is probably not possible to state, neither their exact location nor reasons for their migration are almost impossible to determine. Very likely is the fact that Romani people left their original homeland in several migration waves and probably belonged to different castes which a traditional Indian society is divided into [6].

Forming a separate ethnicity or in other words creating a group of people using their common language, sharing their culture and origin proceeded after their exodus from India. In India itself Romani people merged with the original Indian population. Romani people come to Central and Western Europe in groups numbering from a dozen of men, women and children up to hundreds of members. They come under the supervision of their leaders who are titled as earls. What the entrance of such a group of people to a town was like we learn from a few records, the well-known one is from Paris created in 1427. There it is mentioned that a leader of such a group together with ten horse-riders came as the first and a day later they were followed by a group of more than 100 other people. It is worth mentioning that historical records refer Romani people, in some cases, as Saracens or pagans, respectively Gypsies.

While analyzing Romani community I realized an interesting fact. It is the media that usually fully identify themselves with the opinion of the mainstream society and show members of the minority only when they cause a problem for the majority of people or when they threaten them. The topics related to the everyday life of this minority, such as work, housing, health, education, political life, culture, and discrimination in the areas they live in appear in the media only with the aim to bring a sensation or to pose a problem [8].

On the basis of the theory which is summarized by Petr Bachelor in his book Taboos in the Social Sciences, different races have developed in different ways. According to this theory the highest IQ is a traditional feature of East Asians (Chinese, Koreans, and Japanese) and Jews, followed by Europeans, the people of India, Hispanics, Native Australians, Romani people, and blacks. There are some aspects in Roma community, such as the language, clothes, and occupations (different jobs for men and women) that may vary from group to group. Talking about human population as spread as Romani people, it is necessary to take into account the internal diversity of this ethnic group. Romani language is the most obvious indicator of the origin of Romani people and is closely related to the early modern languages of central and northern India [3].

On the other hand, the origin of Romani cultural practices is much less obvious although there are some observers, activists and even some scientists who tend to look for similarities in the culture of Romani people with the people of the Indian subcontinent. Particularly, they point out similar clothing (especially women's dresses), the way of preparing food, music, dance, funeral rites, and others.

There is another feature of Roma community which is worth mentioning. It is the polarity that is noticeable in a great many of areas, including food, cleanliness of body, and conversational topics as well. One example for all, the upper part of the body is considered to be read without any shame and so men and women can show it without losing respect or being disrespected by other members of Romani community. On the other hand, the lower part of the body is considered dirty. That is the reason why Romani people have to avoid any contact between upper and lower body clothing. In reality it means that clothes covering different parts of the body must be washed separately, in separate containers or washing machines. Moreover, women's clothes, such as skirts and aprons are considered particularly dirty.

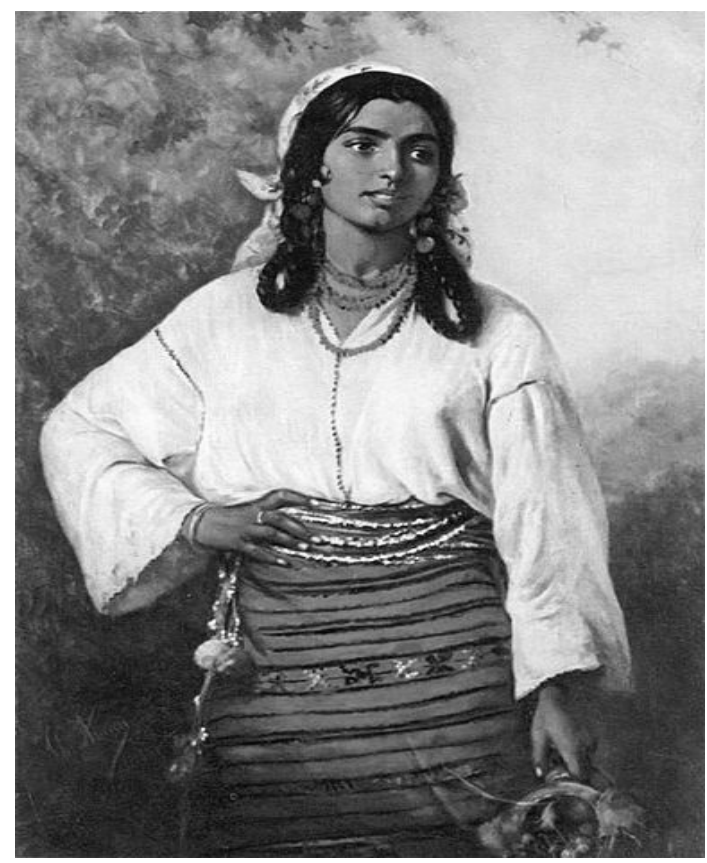

Sources: Gipsy Girl, by Theodor Aman (Romanian 1831-1891), date 1884, National Gallery Bucharest

Chart 2. A Romani girl wearing traditional clothes

Romani women are expected to avoid stepping over any dishes that could be associated with food, especially while sitting at lower or coffee tables. What is more, women must not step over any drinking water sources, such as water tanks either. Based on Romani culture, women are also forbidden to participate in preparation of any dishes during their periods.

Concerning food, there is an interesting tradition in Roma 
community which is still valid somewhere and which is connected with the person who prepares dishes [2]. A great many of Romani people would not eat food that is prepared by gadjo (non-Romani) or by an ethnic Romani who lives in another ethnic subgroup where the concepts of shame and honor may differ in details. On the other hand, there are some Romani people who make no difference between gadjo and Romani people, and are not afraid of pollution of their souls or bodies.

Attitudes to education in Romani community are other interesting themes to discuss. Traditional Romani families educate their children by allowing them to participate in all family activities, including economic ones. Romani children observe, participate in, and gradually take their share of responsibility for other households.

What more, there is no opening ceremony and there is no formal testing of acquired skills and knowledge. Romani people consider school a kind of gadjo institution. While touring the Slovak Republic and talking there with members of Romani communities I learned that it is the school that represents everything that separates Romani people from non-Romani communities. Namely, these are strict rules and obedience to an authority (the teacher) that is not a part of the family. It was evident that school is perceived as a disturbing moment of their everyday life. In fact it is considered as a threat because children are put away from the influence of their parents. Moreover, school is believed to undermine children's confidence in manners and traditions of Romani households.

School also seems to be inconsistent with Romani morality, protection of a family as a unit, and with the natural direction of education in the family that teaches children to rely on their own assessment of a situation rather than follows strict instructions of stereotyped behavior. Moreover, there are some migrating households that rely on the support of their children during seasonal work and thus compulsory school attendance means practical difficulties for them. In spite of the mentioned facts about Romani attitudes to education nowadays they realize the necessity of attending school at least at a young age. Families unwillingly send their children to schools hoping that at least they will benefit from their acquired abilities and key skills, such as basic literacy which can be useful for the family as a whole. A great many of Romani communities have learned to integrate the presence of school facilities to their Romani way of life and try to accept the possibility that their children have to follow the ways of gadjo life [1].

Unfortunately, most Romani parents take their children away from school before they reach puberty. Reasons for such decision vary, but most frequent ones are the fear of drugs, violence, and some threatening behavior. All of them are usually associated with secondary schools or vocational training centers, particularly in disadvantaged areas, or peripheral cities.

Another reason is the fear of estrangement from their home environment. Based on my further empirical research and holding an interview with the former headmistress of the First Private Hotel School in Prague, who has been in her office for nearly ten years, I obtained her information that there has been only one Romani student who has been interested in the hotel industry and gastronomy education. The student started but did not finish the school.

In the Czech lands the first undisputable evidence about Romani people dates back to 1417. A year later another group of Romani people apparently passed through the Czech lands, as evidenced in the records from the towns of Znojmo and Cheb. Then, from 1420s there were some groups of Romani people in Central and Western Europe who possessed some protective safe-conducts and allegations that they had been forced to leave their country by the Turks. On the base of these documents they received alms in individual towns and cities [5].

In 2012 it was estimated by qualified regional offices of the Labor Office of the Czech Republic that there were about 47,854 Romani applicants for a job (compared with 2011there were 38,456 of them). The situation of Romani youth between the ages of 15 and 26 is alarming because $61 \%$ of them face unemployment. What is more, $77 \%$ of them never have had any work experience.

One of the main aims of the ten-year period from 2005 to 2015 is, besides other things, to increase the number of Romani studying craft by about ten percent every year. Then, the average duration of unemployed Romani women and men should be reduced by half. In areas with ghettos employment it is estimated that in a few following decades there will be an increase of unemployed Romani people of $50 \%$. The authorities should work more effectively and offer Romani candidates effective retraining courses or any other support. The reports concerning implementation of these decade tasks state that low qualifications of Romani people, underestimation of their education, worse ability to adapt to needs of employers, and last but not least dependence on benefits which cause the failure of many Romani people in the labor market. Due to the lack of money Romani people are not able to commute to work. They are said to be punished to perform unskilled manual jobs. Moreover, a great many companies are not interested in Romani candidates so they are often unemployed, receive benefits and work illegally [9].

In the education field, the report deals with progress in meeting requirements of the groundbreaking verdict of the European Court of Human Rights in the case D. H. and Others v. the Czech Republic which was passed in 2007. Continually, a significant number of Romani pupils are being educated in former special schools, today often called practical elementary schools. Studies of the Ombudsman and the Czech School Inspectorate carried out last year confirmed that 32 percent of Romani children in the Czech Republic attend the practical schools for children with mild brain injury. Preschool education seems to be problematic as 
well because only $28 \%$ of Romani children do attend kindergartens [10].

The integration of so-called socially inadaptable citizens to labor law processes in hospitality and gastronomy will last in the long haul. On the basis of other of my interviews, in that case with human resources of an anonymous Prague hotel, but one of the world hotel chains, there is no ordinary Romani employee in the hotel. It is necessary to say that all hotels and catering companies solve the employment of socially less adaptable citizens through outsourcing companies that offer these employees to hotels and catering companies in accordance with general contract provisions. However, it usually covers so-called helping hands who participate in washing the dishes, cleaning, room service, or who work as chambermaids. That is the way how some hotel companies avoid possible accusations of racial discrimination and of oppression a minority group.

\section{Methodology}

For the present empirical research a methodology survey was depicted. A part of my empirical research is based on asking questions about Roma community representatives of senior management, such as directors and CEOs, then representatives of middle management, such as heads of various hotel departments, and finally ordinary employees of various hotels and catering companies. There were only three questions on the basis of which I wanted to reveal the overall atmosphere of acceptance of any Romani colleagues in the hotel and catering services in the Czech Republic.

The following questions were asked:

1. Would you mind a Romani person at the same workplace?

2. Would you mind a Romani in a close working team (3-4 people)?

3. Would you mind a Romani as your superior?

On the basis of the answers of above mentioned questions I came to following conclusions, reflected in the graphs:

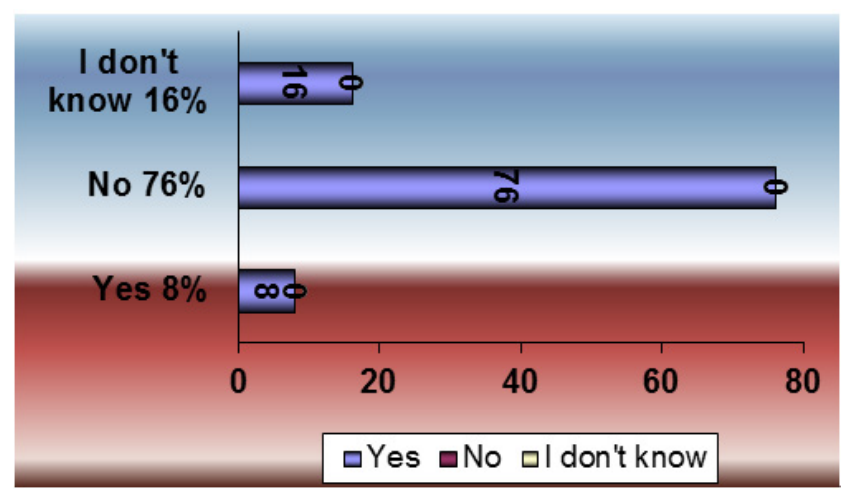

Source: Own chart

Graph 1. Would you mind Romani in the same workplace?
Altogether 40 representatives of senior management were asked the first question "Would you mind a Romani working with you at the same workplace?" 15 of them were directors or executive directors, and mostly foreigners who run various hotel facilities in the Czech Republic. Other 25 respondents were Czech directors of small independent hotels.

$8 \%$ of the respondents answered the question "Yes", $76 \%$ answered "No" and $16 \%$ used the possibility and a choice of an evasive answer "I don't know". Based on these facts one can come to a conclusion that most respondents are tolerant to Roma community and would not mind Romani colleagues at their workplace. The fact is that some of the asked foreigners have some experience with Romani community from their native countries. There is another fact which is indisputable. It is evident that most directors are strictly governed by ethical codes which contain clearly specified regulations concerning behavior and tolerance towards other races and minorities. The regulations are called discriminatory code.

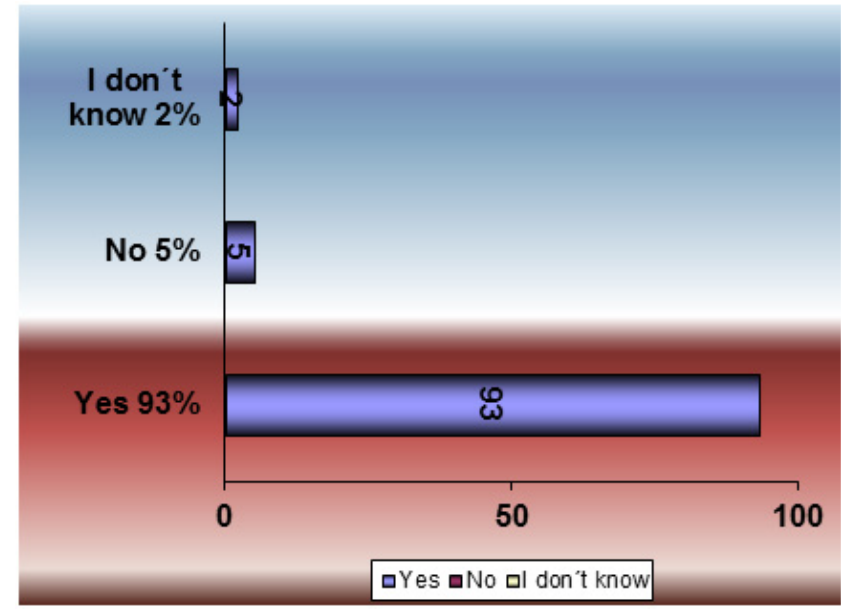

Source: Own chart

Graph 2. Would you mind Romani in a close working team (3-4 people)?

59 representatives of the middle management were asked the second question "Would you mind a Romani in a close working team (3-4 people)?" All of them were Czech and most of them were heads of departments of various hotel facilities in Prague, the Czech Republic.

$93 \%$ of the respondents answered the question "Yes", $5 \%$ answered "No" and $2 \%$ used the possibility and a choice of an evasive answer "I don't know".

Heads of departments are assumed to be also familiar not only with the ethical code but also with the discriminatory code. Based on the results, they might know the code but they do not follow it properly because most of them would not accept the possibility to work with a Romani colleague in a close working team. On the other hand, asking the question I did not feel any hints of racism against Roma people although they strongly oppose against any violation of their teams by other ethnic groups or minorities. 


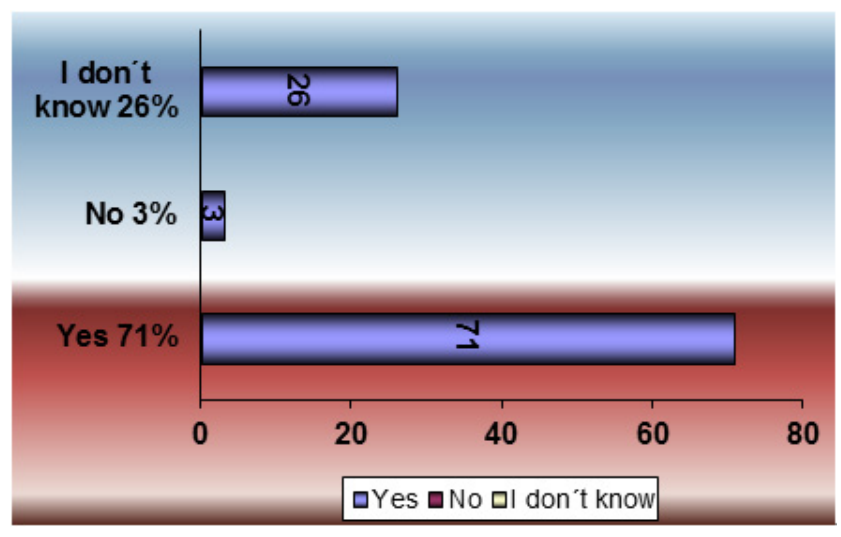

Source: Own chart

Graph 3. Would you mind a Romani as your superior?

82 ordinary employees of hotel and gastronomy services were asked the third question "Would you mind a Romani as your superior?" All of them were of non-Romani origin.

$71 \%$ of the respondents answered the question "Yes", $3 \%$ answered "No" and $26 \%$ of the respondents used the possibility of a choice of an evasive answer "I don't know".

Most of them, while fulfilling their duties, have already met or worked at their workplace with a member of Romani community so it is interesting that most of them would not tolerate a Romani superior. Only three percent of the respondents would have no objections to a Romani manager but they also added that they would also have to do the same job as the others.

\section{Results}

To sum up the research, tolerance of various hotel and catering employees towards a minority group of Romani population is acceptable, but to a certain extent, e.g. through indirect contacts in a close working team. The graph shows that tolerance of Romani community in leading positions equals almost zero. Romani people are said to avoid working, which might be a cause for this way of thinking. Regarding the presence of Romani people at the same working place (hotel or restaurant), it is indisputable that the presence of this minority at the same working place does not meet any objections. Very important is the work of teachers with pupils.

In the case of the Romani it is not the national education teaching in the Roma language, but to create conditions that would allow Roma children to be among Czech pupils and students and achieve primary and secondary education. The Czech school does not differentiate different cultural, social and especially linguistic background from which the Gypsy child comes to school. Low level of education of Roma parents who cannot help children with learning as Czech parents do, low motivation for education and especially the lack of knowledge of the Czech language as the language of instruction - are all barriers that hinder the child to achieve a higher education and get a better perspective for employment, and thus life. A gypsy child does not manage to follow the commentary; they often do not understand what the teacher wants from them. A Roma child in fact meets the standards written in Czech for the first time only at school, because at home they hear the mixture ofCzech and Slovak, enriched by Roma expressions.

Czech schools also focus on the development of entirely rational aspects of a personality and only cultivate rational thinking. Due to such thinking a Czech child is conducted by various games and toys that train logical solution to the problem. A gypsy child for the first time meets the requirements for logic at school and thus inevitably fails. Therefore, since 1993 several variants of education of Roma children have been approved. They aimed at preparations of education in the Czech language, at helping Roma children to overcome initial disadvantages of learning in the Czech language and Czech culture. More and more schools provide the help of Roma assistants who mediate contacts between Roma children and their teachers.

\section{Discussion and Conclusions}

The issue of employment of Romani people in hospitality and gastronomy has its origin in their education. And in their cohabitation with the majority of the society that has been fighting these problems for a long time. The fact is that Romani children are not very interested in jobs as cooks or waiters, and they do not apply for studies at secondary schools focusing on gastronomy and hospitality. A Romani student is considered rather an exception. If we want to solve this problem, the state should try to do more for deeper assimilation of Romani students in these branches. On the other hand, Roma community should also try to change some matters, such as their attitudes to education of their children. Finally, there is another thing that should be changed. It is the general public view of Roma community as a whole, which is not and will not be easy.

Romani culture does not differ from the culture of gadjo. It has its purpose, namely the maintenance of the community and family at its very core. At the same time we have to always bear in mind that Romani culture, like other cultures, is not static but dynamic, and is a subject to a number of variations and changes. Inevitably, social changes lead to cultural changes. The reality of Romani culture is a complicated and multi-layered problem that has to be solved in the future. Many Romani have adopted - and in an extreme form - consumerist mentality of our society, which is a spiritual vacuum rather than its fulfillment. Sometimes a community loses its spiritual roots, as for the Romani it has become the fact. It seems that they lack any immunity against brainwashing. No nation can live in the spiritual vacuum as represented by various religious streams in the country. In the past regime and in some countries the Roma community gained the position of non-qualified labor force and in parallel a range of social advantages, as for example 
accommodation facilities financed by the state, decent income. However they were not supported either attracted in further improvement of their own living standard. The fall of the communist regime connected with possible unemployment brought changes in the life of those Romani who were used to work, feared the life of a sponger or avoidance of working activities.

The Romani who wanted to keep their jobs had to work much harder because their employers practiced stronger selection compared with the members of the majority. Quite a number of the Romani diverted into the field of shadow economy that employs them as easily accessible labor force. In accordance with the system of social benefits these companies observe this practice as a good advantage. At the same time most Romani do not seriously consider the matter of education to be their advantage. Exclusion of the Romani from the labor market should force public institution to towards a long-lasting and complete strategy of these matters solutions. The priority should be devoted to the support of disadvantaged groups of the population via implementation of a broad scale of measures in the field of social services, education, programs offering employment and support of prevention of social pathological phenomena.

The prime goal of the long-lasting governmental strategy aiming at the Romani integration is improvement of the Romani position in all matters of the society life where there exist unacceptable differences between the majority of the community and a substantial part of the Romani. Such a strategy can secure non-conflicting cohabitation of the Romani and the rest of the population. The government has set up the goal - by 2025 to succeed better living cohabitation of the Romani and the rest of the society, and namely in the key fields as education and labor market. Such specific arrangements as 'equalizing programs' should not be necessary to be practiced any more. [8].

\section{REFERENCES}

[1] Okely, J. The Traveller - Gypsies. Cambridge: Cambridge University Press, 1983

[2] Gay, Blasco, P. Gypsies in Madrid: Sex, Gender and the Performance of Identity. Berg Publishers, 1999.

[3] Matras, Y. The Role of Language in Mystifying and De mystifying Gypsy Identity. In: The role of the Romanies, edited by Saul, N. \& Tebbut, S. Liverpool: Liverpool University Press. 53-78, 2004

[4] Source: Gipsy Girl, by Theodor Aman (Romanian 1831/1891) 1884, National Gallery Bucharest

[5] Source: Lhotka, P., BL, Where the Roma Actually Come from? / Http://blisty.cz/art/20183.html \# sthash.DbQn0VoL.dpuf

[6] Sources: available: www. romove.radio.cz/cz/article/18530 Source : available : http://cs.wikipedia.org/wiki/Romov \% C3 \% A9, the Roma population - the average occupancy distribution

[7] Source : Government Agency for Social Inclusion analysis covers the period $07 / 2011$ to $05 / 2012$, Prague, $84^{\text {th }} 2013$

[8] Source: www.novinky.cz/economic/314989-romu-bez-prace-vyraznepribyva.html

[9] Source: www.romea.cz /.... / Government - discuss -News of-state -Roma - minority - per -ro. 